\title{
Mobile cellular telephones and children
}

\author{
Sri Lanka Journal of Child Health, 2012; 41(1): 1-2
}

(Key words: mobile cell phone; child)

The use of mobile cellular telephones, also known as cell phones and mobile phones, by children has in recent years been increasing, the onset starting earlier and earlier. This has led to concern about whether children might be at higher risk and whether mobile phone use should even be curtailed in children. Certainly for parents, giving children mobiles help to keep tabs on them when they are out and about in a world full of hazards. However, if the hazard is the phone itself, then we would be wise to take precautions. In July 2009 Sri Lankan Ministry of Education banned students from taking mobile phones to school after a 14-year-old girl hanged herself after being reprimanded over a telephone contact with a boy during school ${ }^{1}$.

Cell phones emit radiofrequency energy, a form of non-ionizing electromagnetic radiation, which can be absorbed by tissues closest to where the phone is held. The amount of radiofrequency energy to which a cell phone user is exposed depends on the technology of the phone, the distance between the antenna of the phone and the user, the extent and type of use and the distance of the user from cell phone towers ${ }^{2}$. Electromagnetic radiation can be categorized into two types viz. ionizing (e.g. X-rays) and nonionizing (e.g. radiofrequency) ${ }^{3}$. Exposure to ionizing radiation is known to increase the risk of cancer. There is no consistent evidence that non-ionizing radiation increases the cancer risk ${ }^{3}$. It is accepted that DNA damage is necessary for development of cancer. However, radiofrequency energy, unlike ionizing radiation, does not cause DNA damage in cells and has not been found to cause cancer in animals or to enhance the cancer-causing effects of known chemical carcinogens in animals ${ }^{4-6}$.

Theoretically, children are potentially at greater risk for developing brain cancer from cell phones than adults. Their developing nervous systems are more vulnerable to factors that may cause cancer. Their smaller heads have a greater proportional exposure to the field of radiofrequency radiation emitted by cell phones. Furthermore, children have the potential of accumulating more years of cell phone exposure than adults $^{2}$. So far, data from clinical studies in children do not support this theory. Aydin et $\mathrm{al}^{7}$ provide results from the first study specifically designed to address cell phone use among children and adolescents diagnosed with brain tumours. They conducted a caseï control study of children and adolescents 7 to19 years of age in Denmark, Norway, Sweden, and Switzerland. Three hundred and fifty two children who were diagnosed in 2004 ï 2008 with a brain tumour were identified from various clinicand population-based registry records and 646 controls were randomly selected from the general population. Cell phone use was estimated based on face-to-face interviews with a parent present and from cell phone subscriber records when available. Researchers did not find an association between cell phone use and risk of brain tumour in this group of children. However, they noted that their results did not rule out the possibility of a slight increase in brain cancer risk in children who use cell phones, and that data gathered through prospective studies and objective measurements, rather than participant surveys and recollections, will be key to clarifying whether there is an increased risk ${ }^{7}$.

The U.S. Food and Drug Administration and the Federal Communications Commission have suggested some steps that cell phone users can take to reduce their exposure to radiofrequency energy ${ }^{3}$.

- Reserve cell phone use to shorter conversations or when a landline phone is not available.

- Use a hands-free device placing more distance between the phone and the head of the user

The Danish National Birth Cohort (DNBC) looked at prenatal and postnatal exposure to cell phone use and behavioural problems at age 7 years. Mothers were recruited to the DNBC early in pregnancy. When the children of those pregnancies reached 7 years of age in 2005 and 2006, mothers were asked to complete a questionnaire regarding the current health and behavioural status of children, as well as past exposure to cell phone use. Mothers evaluated the child's behaviour problems using the Strength and Difficulties Questionnaire. The authors of the study concluded that exposure to cell phones prenatally, and to a lesser degree postnatally, were associated 
with behavioural difficulties at around 7 years of age $^{8}$. A larger, separate group of DNBC children produced similar results after considering additional confounders. This ónewô dataset consisted of 28,745 children with completed age-7 questionnaires to December 2008. The highest Odds Ratio for behavioural problems were for children who had both prenatal and postnatal exposure to cell phones compared with children not exposed during either time period. The adjusted effect estimate was 1.5 (95\% CI 1.4 to 1.7$)^{9}$.

One study investigated the potential effects of a standard $902 \mathrm{MHz}$ global system for mobile communication mobile phone on the cognitive function of 10-14 year old children. A total of 32 children performed a battery of cognitive tests twice, once while exposed to an active mobile phone and once during exposure to an inactive phone. The statistical analyses showed no significant differences between the mobile phone off and on conditions in reaction times and accuracy over all tests or in any single test. It was concluded that a standard mobile phone has no effect on children's cognitive function as measured by response speed and accuracy ${ }^{10}$.

In another study ${ }^{11}$ seventy seven children aged 10 to 11 years completed simulated road crossings in a virtual pedestrian environment. Children crossed the virtual street 6 times while undistracted and 6 times while distracted by a cell phone conversation. While distracted, children were less attentive to traffic, left less safe time between their crossing and the next arriving vehicle, experienced more collisions and close calls with oncoming traffic and waited longer before beginning to cross the street ${ }^{11}$.

\section{References}

1. Sri Lanka bans mobile phones at schools after suicide. Lanka Business Online. Available from: file:///J:/MOBILE\%20PHONES/Mobile\%20pho ne\%20ban\%20in\%20schools.htm

2. National Cancer Institute Fact Sheet. Cell phones and cancer risk. Available from: file://JJ:/MOBILE\%20PHONES/Cell\%20phones \%20and\%20cancer\%20risk.htm

3. Volkow ND, Tomasi D, Wang GJ, et al. Effects of cell phone radiofrequency signal exposure on brain glucose metabolism. JAMA 2011; 305(8): $808 і ̈ 13$. http://dx.doi.org/10.1001/jama.2011.186
4. Hirose H, Suhara T, Kaji N, et al. Mobile phone base station radiation does not affect neoplastic transformation in BALB/3T3 cells. Bioelectromagnetics 2008; 29(1):55ï 64. http://dx.doi.org/10.1002/bem.20362

5. Oberto G, Rolfo K, Carbonatto $\mathrm{M}$, et al. Carcinogenicity study of $217 \mathrm{~Hz}$ pulsed electromagnetic fields in Pim1 transgenic mice. Radiation Research 2007; 168(3):316ï 26. http://dx.doi.org/10.1667/rr0425.1

6. Zook BC, Simmens SJ. The effects of pulsed 860 $\mathrm{MHz}$ radiofrequency radiation on the promotion of neurogenic tumors in rats. Radiation Research 2006; 165(5):608ї 15. http://dx.doi.org/10.1667/RR3551.1

7. Aydin D, Feychting M, Schüz J, et al. Mobile phone use and brain tumors in children and adolescents: a multicenter case-control study. Journal of the National Cancer Institute 2011; 103:1ï 13 . http://dx.doi.org/10.1093/jnci/djr244

8. Divan HA, Kheifets L, Obel C, Olsen J. Prenatal and postnatal exposure to cell phone use and behavioural problems in children. Epidemiology 2008; 19(4):523-9. http://dx.doi.org/10.1097/EDE.0b013e318175dd $\underline{47}$

9. Divan HA, Kheifets L, Obel C, Olsen J. Cell phone use and behavioural problems in young children. $J$ Epidemiol Community Health doi:10.1136/jech.2010.115402. Available from: file:///J:/MOBILE\%20PHONES/Cell\%20phone \%20use\%20and\%20behavioural\%20problems.ht $\underline{\mathrm{m}}$

10. Haarala C, Bergman M, Laine M, Revonsuo A, Koivisto $M$, Hämäläinen $H$. Electromagnetic field emitted by $902 \mathrm{MHz}$ mobile phones shows no effects on children's cognitive function. Bioelectromagnetics 2005; Suppl 7:S144-50. http://dx.doi.org/10.1002/bem.20142

11. Stavrinos D, Byington KW, Schwebel DC. Effect of cell phone distraction on paediatric pedestrian injury risk. Pediatrics 2009; 123(2): e179-e185. http://dx.doi.org/10.1542/peds.2008-1382

G N Lucas

Joint Editor 